\title{
Anti-oviposition activities of used sock media against a dengue vector: prospects of eco-friendly control and solutions to pollution
}

\author{
Hamady Dieng ${ }^{1} \cdot$ Tomomitsu Satho $^{2} \cdot$ Fatimah Abang $^{3} \cdot$ Fumio Miake $^{2}$. \\ Idris A. Ghani ${ }^{4}$ - Nurshilawati A. Latip ${ }^{3}$ - Nur Ezzati Aliasan ${ }^{3}$ - Sabina Noor ${ }^{3}$. \\ Abu Hassan Ahmad ${ }^{5}$ - Hamdan Ahmad ${ }^{5}$. Wan Fatma Zuharah ${ }^{5}$. \\ Abdul Hafiz Ab Majid ${ }^{5}$. Cirilo Nolasco-Hipolito ${ }^{3}$ - Ronald Enrique Morales Vargas ${ }^{6}$. \\ Noppawan Phumala Morales ${ }^{7}$. Gabriel Tonga Noweg ${ }^{1}$
}

Received: 23 October 2016 / Accepted: 26 June 2017

(C) Springer-Verlag GmbH Germany 2017

\begin{abstract}
Yearly, huge amounts of sock refuse are discarded into the environment. Socks contain many molecules, and worn ones, which are rich in smell-causing bacteria, have a strong influence on animals' behaviors. But the impacts of sock odor on the oviposition behavior of dengue vectors are unknown. We assessed whether Aedes albopictus changes its oviposition activity in response to the presence of used socks extract (USEx) in potential breeding grounds, using choice and no-choice bioassays (NCB). When furnished even chances to oviposit in two sites holding USEx and two others containing water (control), Ae. albopictus deposited significantly less eggs in USEx than in water sites. A similar pattern of oviposition preference was also observed when there were
\end{abstract}

Responsible editor: Philippe Garrigues

Hamady Dieng

hamadydieng69@gmail.com

1 Institute of Biodiversity and Environmental Conservation (IBEC), Faculty of Resource Science and Technology, Universiti Malaysia Sarawak, Kuching, Kota Samarahan, Malaysia

2 Faculty of Pharmaceutical Sciences, Fukuoka University, Fukuoka, Japan

3 Faculty of Resource Science and Technology, Universiti Malaysia Sarawak, Kota Samarahan, Malaysia

4 Faculty of Science and Technology, Universiti Kebangsaan Malaysia, Bangi, Malaysia

5 School of Biological Sciences, Universiti Sains Malaysia, Penang, Malaysia

6 Department of Medical Entomology, Faculty of Tropical Medicine, Mahidol University, Bangkok 10400, Thailand

7 Department of Pharmacology, Faculty of Science, Mahidol University, Bangkok 10400, Thailand more oviposition options in water. When there were greater oviposition opportunities in USEx sites, Ae. albopictus oviposited preferentially in water. Females laid significantly more eggs during the NCB involving water than USEx. Also, significantly more mature eggs were retained by females in the NCB with USEx than in that with water. These observations strongly suggest the presence of molecules with either repellent or deterrent activities against Ae. albopictus females and provide an impetus to advocate the integration of used socks in dengue control programs. Such applications could be a realistic end-of-life recourse to reroute this waste from landfills.

Keywords Sock waste $\cdot$ Dengue vector · Oviposition repellence $\cdot$ Egg retention

\section{Introduction}

Dengue viruses are still a continuous public health threat worldwide (Messina et al. 2013; Fares et al. 2015). Previously thought of as the main flavivirus transmitted by female Aedes mosquitoes, these viruses have been surpassed by Zika virus in many dengue endemic areas (Hennessey et al. 2016), causing a public health emergency of international concern (WHO 2016). Chemical insecticides - the principal strategy against dengue vectors (WHO/WPR 2010) - have become ineffective due to the development of resistance among mosquito populations (Whalon et al. 2008; Wilke and Marrelli 2015) and the narrowing spectrum of effective agents (Dusfour et al. 2010). Therefore, it is becoming increasingly necessary to search for alternative vector control strategies. 